\title{
Research on Competitive Multi-facility Location with Market Expansion
}

\author{
Guoying $\mathrm{Wu}^{1}$, Jianqin $\mathrm{Zhou}^{1}$ and Bei Wang ${ }^{2}$ \\ ${ }^{1}$ School of Economics and Management, Beijing Jiaotong University, China \\ ${ }^{2}$ School of Public Administration, University of International Business and \\ Economics, China \\ \{12120632,jqzhou\}@bjtu.edu.cn,wangbei@uibe.edu.cn
}

\begin{abstract}
It is critical to locate facilities in the retail operations, especially in competitive environment. In most competitive location models available in the literatures, demand is assumed to be fixed or random regardless of market conditions. However, demand is related to the number of facilities, service capacity or the distance from the facility to the customer, which is considered in few literatures. In this paper, a competitive multi-facility location model with fixed demand is established and then market expansion is taken into account in the model. The Plant Growth Simulation Algorithm (PGSA) is put forward to solve the two models and then a small numerical example is given. Compared to the problem with fixed demand, the optimum solution of facility location is variable and the profit increases obviously with market expansion considered.
\end{abstract}

Keywords: Competitive Location; Market Expansion; Fixed Demand; Plant Growth Simulation Algorithm

\section{Introduction}

Location of retail facilities has been a research focus in the field of management decisions. In today's increasingly competitive environment, the location plan has a direct impact on the market shares that a company captured. In a competitive location problem, the facilities to be located will compete with the existing ones. Hotelling [1] defined the competitive location firstly and assumed that all facilities had the same attraction and the customer would choose the services and facilities in accordance with the principle of proximity. After that, a number of scholars inherited Hotelling's idea and studied the competitive location model from different angles and formed a group of models and theories about competitive location.

Observe that in most competitive location literatures, it is assumed that the demand is fixed or random regardless the conditions of the market. Researches with fixed demand are applied in [1-5] and the references therein, Plastria [2] studies the location problem with fixed demand and customers patronize only the facility that attracts them most. Hua et al. [3] study the network competitive location model with fixed demand. Meng et al. [4] study the continuous competitive location model with fixed logistics services. Duan et al. [5] study the competitive location of a new logistics center problem with constant demand. While random demand are adopted in [6-8] and the references therein, Dasci and Laporte [6] study a single large enterprise facility siting and pricing decisions model with the demand obeys a linear function. Yang et al. [7] study multilayer loop competitive supply chain network equilibrium model with stochastic

Corresponding author, Jianqin Zhou 
demand. Bi et al. [8] use the trigonometric functions to simulate the fuzzy demand, constructing a multi-objective model of discrete random location model.

Although fixed demand or random demand assumption may be appropriate for essential goods, in other cases this is mainly due to the difficulty of solving the problems. However, sometimes demand is elastic, which varies depending on several factors, especially for nonessentials. For instance, the customer demand may be increase for a variety of reasons related to the new facilities: the higher overall service level and the closer to the customer who did not patronize the facilities which are away from them. Currently, elastic demand and market expansion have aroused the interest of researchers', see [9-13]. Eiselt and Laporte [9] study facility location and design models with elastic demand. Both market expansion and market cannibalization are considered in [10], in which customer demand is assumed to be a concave non-decreasing function in the spatial interaction model. The spatial interaction model is considered to locate and design the facility with elastic demand in [11]. Both market expansion and market cannibalization of the chain-company's existing facilities are considered in [12] and a dual objective model to maximize the market share and to minimize the cannibalization of its existing facilities is formulated. Juana and Jose [13] give a single facility location and design model with fixed demand and elastic demand. Elastic demand is the common ground in [9-13] to locate a single facility. While these papers about competitive location with elastic demand are confined to a single facility location, few literatures focus on several facilities locations.

Customer behavior is essential for a given company to capture the service demand. Customers are more likely to visit a facility with higher service level and more convenience, and they would like to spend more. The general framework of "spatial interaction models" was adopted to describe the customer behaviors classically in the fields of geography, economics and marketing, which originated from Huff [14]. Under this framework, it is assumed that customer choice rules are probabilistic, i.e., that the customers split their demand between several (possibly all) of the available facilities, with the frequency (probability) of a visit to a particular facility decreasing with the distance from the facility and increasing with the "attractiveness" of the facility. After that, a number of scholars discuss this class of competitive location models. Some typical researches are of Berman, Krass and McLafferty. Berman and Krass [15] combine the features of the spatial interaction and flow interception models, which propose a flexible new model for the location of competitive facilities. Berman and Krass [10] introduce non-constant expenditure functions into spatial interaction location models. Ghosh, McLafferty and Craig [16] investigate the multifacility location model in continuous space using spatial interaction models in Drezner.

The purpose of this paper is to reconsider the analysis in [13] and to discuss competitive multi-facility location with market expansion. A competitive multi-facility location model is built with fixed demand and then a model with market expansion (see Section 2). In particular, as the multi-facility location is hard to solve, so in section 3, we will introduce the principle and procedures of the Plant Growth Simulation Algorithm (PGSA) to cope with the two models. A small numerical example is carried out in Section 4 to demonstrate the PGSA's effectiveness and compare the differences in optimum solution and profits between fixed demand and market expansion. Finally, some conclusions and future research are pointed out in Section 5. 


\section{Problem Description and Modeling}

\subsection{Problem Description}

The location problem is divided into discrete location and continuous location. In this paper, a discrete competitive location is discussed. Market expansion refers to demand increasing with more facilities and more convenient to customers. The situation described in this paper is: Some new facilities will be located by a retail company in a given candidate region, where there are some facilities owned by the retail company and the others by the competitors. Demands are concentrated at some points and their locations are known. The location and service level of existing facilities are also fixed. The location cost of a new facility includes the service desks cost and renting cost. The nearer to the demand points, the more renting cost is needed. The operation cost is ignored in this paper. The function of sales is linear in order to simplify the calculations, for details, see [13].

There are no price differences between the new facilities and the existing ones. Following the framework of spatial interaction models introduced by Huff [14], the patronizing behavior of customers is probabilistic. In other words, customers split their demands in accordance with the facility attractions. The service level of new facilities, which is measured by service desk, is a balance between cost and customer satisfaction.

\subsection{Notation Explanation}

The following notation will be used throughout this paper:

Sets

$\mathrm{N} \quad$ the set of demand points, $N=\{1,2, \ldots, n\}, i \in N$

E the set of existing facilities, $E=\{1,2, \ldots, n\}, j \in E$

$\mathrm{S} \quad$ the set of new facilities, $S=\{1,2 \ldots, m\}, k \in S$

Parameters

$\begin{array}{cl}x_{k} & \text { the possible location of new facilities, } x_{k} \in S \\ \alpha_{j} & \text { the service level of existing facilities } j,\left(\alpha_{j}>0\right) \\ \alpha_{k} & \text { the service level of new facilities } \mathrm{k} \\ \alpha_{\text {min }} & \text { minimum service level } \\ \alpha_{\text {max }} & \text { maximum service level } \\ P_{i} & \text { the probability of a demand point } i \text { selecting the facilities of the retail company } \\ q_{i} & \text { location of demand point, } i=1,2, \ldots, n \\ \omega_{i} & \text { fixed demand at } q_{i} \\ \omega_{i}^{\text {max }} & \text { maximum demand at } q_{i} \\ \omega_{i}^{\text {min }} & \text { minimum demand at } q_{i} \\ \lambda_{k} & \text { weight for the utility of the new facility as perceived by demand point } \mathrm{k} \\ d_{i j} & \text { distance between demand point } \mathrm{i} \text { and facility } \mathrm{j} \\ d_{i k} & \text { distance between demand point } \mathrm{i} \text { and facility } \mathrm{k} \\ d_{i j}^{\text {min }} & \text { minimum distance from demand point } \mathrm{i} \text { at which the new facility } \mathrm{j} \text { can be located. } \\ g_{i}(\cdot) & \text { a non-negative non-decreasing function } \\ \theta & \text { the income of per unit goods } \\ c_{k} & \text { renting cost of the new facility } \mathrm{k} \\ h & \text { the cost of a service desk } \\ u_{i j} & \text { attraction that demand point } q_{i} \text { feels for the existing facility } \mathrm{j}, \\ u_{i k} & \\ M & \text { attraction that demand point } q_{i} \text { feels for the new facility } \mathrm{k}, u_{i j}=\quad u_{i j}=\alpha_{j} / g_{i}\left(d_{i j}\right) \\ F & \text { profits obtained by the retail company }\end{array}$




$$
\text { C the cost of the new facilities }
$$

\subsection{Competitive Multi-Facility Location Model}

2.3.1. The Competitive Multi-facility Location with Fixed Demand: In a given region, $m$ new facilities will be located by the retail company $A$, where there are $r$ facilities offering the same service and their service level are known. The first $l(0 \leq l<r)$ facilities belong to the company $A$. Here $l=0$ means that there are no existing facilities owned by the company $A$ in the given region. The demands are concentrated at $n$ points, whose locations and quantities are known. The probability of a demand point $i$ selecting the facilities owned by the company $A$ can be defined as Eq. (1). $\sum_{k=1}^{m} u_{i k}+\sum_{j=1}^{l} u_{i j}$ represents the utility of the company $A$, while $\sum_{k=1}^{m} u_{i k}+\sum_{j=1}^{r} u_{i j}$ indicates the overall utility of all facilities.

$$
P_{i}=\frac{\sum_{k=1}^{m} u_{i k}+\sum_{j=1}^{l} u_{i j}}{\sum_{k=1}^{m} u_{i k}+\sum_{j=1}^{r} u_{i j}}
$$

Therefore, the market demands captured by the company $A$ can be expressed as Eq. (2), in which $\omega_{i} P_{i}$ means the demand captured by the company $A$ at demand point $i$.

$$
M=\sum_{i=1}^{n} \omega_{i} P_{i}
$$

As the function of sales is linear, we use $\theta$ to transform the market demand into sales, where

$\theta$ is the income of per unit goods. The sales of company $A$ can be described by Eq. (3).

$$
F=\theta \sum_{i=1}^{n} \omega_{i} P_{i}
$$

The renting cost is increasing with the demand and decreasing with the distance from facility to customer. The closer to the demand points, the higher renting cost will be cost. As the same to the literature [13], we definite the renting cost for the $k$ new facilities as Eq. (4).

$$
c_{k}=\sum_{i=1}^{n} \frac{\omega_{i}}{g^{2}\left(d_{i k}\right)+1}
$$

Therefore, the total cost of new facilities owned by company $A$ can be expressed as Eq. (5), in which $\sum_{k=1}^{m} h \alpha_{k}$ represents the cost of service desks.

$$
C=\sum_{k=1}^{m} c_{k}+\sum_{k=1}^{m} h \alpha_{k}
$$

In summary, the competitive location problem with fixed demand can be stated as

$$
\text { Maximize } Z=\theta \sum_{i=1}^{n} \omega_{i} P_{i}-\left(\sum_{k=1}^{m} c_{k}+\sum_{k=1}^{m} h \alpha_{k}\right)
$$

Subject to

$$
\begin{aligned}
& P_{i}=\frac{\sum_{k=1}^{m} u_{i k}+\sum_{j=1}^{l} u_{i j}}{\sum_{k=1}^{m} u_{i k}+\sum_{j=1}^{r} u_{i j}} \\
& c_{k}=\sum_{i=1}^{n} \frac{\omega_{i}}{g^{2}\left(d_{i k}\right)+1} \\
& \alpha \in\left[\alpha_{\text {min }}, \alpha_{\text {max }}\right] \\
& \lambda_{k}, \theta \in[0,1]
\end{aligned}
$$




$$
\begin{aligned}
& d_{i j} \geq d_{i j}^{\min }, \forall i, j \\
& x_{k} \in S
\end{aligned}
$$

The objective function is to maximize the total profit of the retail company $A$, where the first part is sales obtained by the company $A$, and the second part is the service desks cost and renting cost. Eq. (7) states the probability of a customer $i$ selecting the facilities of company $A$. Eq. (8) defines the renting cost of new facilities. Eq. (9) and Eq. (10) give the range of $\lambda_{k}, \theta$ and $\alpha$. Eq. (11) guarantees that the new facilities are not located on top of demand points, which is the same to the literature [13]. Eq. (12) denotes that the new facilities should be located in the given region.

2.3.2. The Competitive Multi-facility Location Problem with Market Expansion: In the previous model, the demand $\omega_{i}$ is assumed to be fixed at all demand points. Now let us discuss the competitive location with market expansion. Some demands captured by company $A$ are from customers of existing facilities and some are from market expansion. The elastic demand at demand point $q_{i}$ is affected by the perceived utility of all facilities, given by the vector $u_{i}=\left(u_{i 1}, u_{i 2}, \ldots . u_{i r}, u_{i r+1} \ldots . u_{i r+m}\right)$. The utility is additive, so $U_{i}=\sum_{k=1}^{m} u_{i k}+$ $\sum_{j=1}^{r} u_{i j}$. For the customer at $q_{i}, U_{i}$ is the total utility provided by all facilities. Then the demand at $q_{i}$ is $\omega_{i}\left(U_{i}\right)$.

If $\omega_{i}^{\text {max }}$ denotes the maximum possible demand at $q_{i}, \omega_{i}^{\text {min }}$ denotes the minimum possible demand at $q_{i}$, then the actual demand $\omega_{i}$ at $q_{i}$ is a function of the utility vector $u_{i}$ only through the total utility $U_{i}$, i.e., $\omega_{i}\left(U_{i}\right)=\omega_{i}^{\text {min }}+\left(\omega_{i}^{\text {max }}-\omega_{i}^{\text {min }}\right) * e_{i}\left(U_{i}\right)$. Here, $e_{i}\left(U_{i}\right)=\delta * U_{i}$ and $\delta$ is a given constant such that $\delta \leq \frac{1}{U_{i}^{\text {max }}} . U_{i}^{\text {max }}$ is the maximum utility that can possibly be perceived by a customer at $q_{i}$. For different possible expressions of $\omega_{i}\left(U_{i}\right)$, see [13]. So, in the Eq. (6) and Eq. (8) $\omega_{i}$ is changed to $\omega_{i}\left(U_{i}\right)$, the model will be expressed as follow.

Subject to

$$
\text { Maximize } Z=\theta \sum_{i=1}^{n} \omega_{i}\left(U_{i}\right) P_{i}-\left(\sum_{k=1}^{m} c_{k}+\sum_{k=1}^{m} h \alpha_{k}\right)
$$

$$
\begin{aligned}
& P_{i}=\frac{\sum_{k=1}^{m} u_{i k}+\sum_{j=1}^{l} u_{i j}}{\sum_{k=1}^{m} u_{i k}+\sum_{j=1}^{r} u_{i j}} \\
& c_{k}=\sum_{i=1}^{n} \frac{\omega_{i}\left(U_{i}\right)}{g^{2}\left(d_{i k}\right)+1} \\
& \alpha \in\left[\alpha_{\text {min }}, \alpha_{\text {max }}\right] \\
& \lambda_{k}, \theta \in[0,1] \\
& d_{i j} \geq d_{i j}^{\text {min }}, \forall i, j \\
& x_{k} \in S
\end{aligned}
$$

\section{Solving the Location Model with Plant Growth Simulation Algorithm (PGSA)}

Heuristic algorithms have been applied in the competitive location extensively, such as simulated annealing, genetic algorithm, ant colony algorithm, greedy algorithm, tabu search algorithm and plant growth simulation algorithm (PGSA) [3-5, 7, 13, 15]. In [17], the Plant Growth Simulation Algorithm (PGSA) is studied for solving the Weber multi-facility location 
problem. The application in the location problem shows that there are good characteristics of PGSA, such as high accuracy, good stability, and strong application.

Plant Growth Simulation Algorithm (PGSA) [17] is an intelligent optimization algorithm, which is a kind of growth model that is mainly based on plant growth theory and the plant phototropism rules. As the parameters are simple and relaxed, there are lots of applications of the algorithm. So far, the main application areas are the network layout optimization, engineering and technical fields. The Plant Growth Simulation Algorithm (PGSA) is applied to the competitive models and the steps of Plant Growth Simulation Algorithm (PGSA) algorithm are as follows:

Step1: The system randomly generates growth points $x_{k}$.

Step2: Calculating the probabilities of growth points $x_{k}$ with the following function, $P_{i}=f\left(S_{a_{p} b_{q}}^{k}\right) / \sum_{i_{1}=1}^{n} \sum_{k_{1}=1}^{m_{i 1}} f\left(S_{a_{p} b_{q}}^{0}\right)+\sum_{i_{2}=1}^{n} \sum_{k_{2}=1}^{m_{i 2}} f\left(S_{a_{p} b_{q}}^{1}\right) \ldots+\sum_{i_{k+1}=1}^{n} \sum_{k_{k+1}=1}^{m_{i k}} f\left(S_{a_{p} b_{q}}^{k}\right)$, here, $s_{a_{p} b_{q}}^{k}$ states the $b_{q}$ th growth point of the $a_{p}$ th truck or branch.

Step3: According to calculation results of Step 2, generate a random number in 0-1 space, and select a growth point $x_{k}$ as the iteration point.

Step4: Determine the step $\delta$, then the growth point grows according to L-system with angle $=90^{\circ}$.

Step5: If no new growth points are generated or the iteration times achieve the given upper limit, then optimum solution is obtained, downtime. Otherwise, back to Step2.

\section{Computational Studies}

In order to study the impact of market expansion on facility location and profits, without loss of generality, we assume that there are 20 demand points, and competitors have two facilities in the market, new facilities can be located at any points except for the demand points. Currently, there are no facilities belonging to company $A$ and some new facilities to be located. To simplify the calculation, the parameters are set as follows: $n=20, \theta=1$, $\lambda_{k}=0.75, \quad \alpha_{j}=\alpha_{k}=5, \quad h=0.6, \quad r=2, \quad \mathrm{k}=0$.

Assuming a rectangular area, with the range from $(0,0)$ to $(100,100)$, which exists 20 randomly generated scattered demand points, the coordinates of demand points are shown in Table 1. The fixed demand, the maximum demand and the minimum demand of each point are shown in Table 2 . Facility 2 and facility 13 belong to the competitors.

Table 1. The Coordinates of Demand Points

\begin{tabular}{c|c|c|c|c|c}
\hline \multirow{2}{*}{ No } & \multicolumn{2}{|l|}{$\begin{array}{l}\text { The coordinates of demand } \\
\text { points }\end{array}$} & \multirow{2}{*}{ No } & \multicolumn{2}{|l}{$\begin{array}{l}\text { The coordinates of demand } \\
\text { points }\end{array}$} \\
\cline { 2 - 3 } \cline { 5 - 6 } & $a_{1}$ & $a_{2}$ & & $a_{1}$ & $a_{2}$ \\
\hline 1 & 1.00 & 0.00 & 11 & 56.00 & 34.00 \\
\hline 2 & 35.00 & 21.00 & 12 & 17.00 & 42.00 \\
\hline 3 & 70.00 & 94.00 & 13 & 53.00 & 64.00 \\
\hline 4 & 10.00 & 69.00 & 14 & 78.00 & 26.00 \\
\hline 5 & 16.00 & 81.00 & 15 & 37.00 & 58.00 \\
\hline 6 & 82.00 & 95.00 & 16 & 17.00 & 80.00 \\
\hline 7 & 95.00 & 83.00 & 17 & 40.00 & 24.00 \\
\hline 8 & 45.00 & 60.00 & 18 & 49.00 & 98.00 \\
\hline 9 & 54.00 & 72.00 & 19 & 6.00 & 7.00 \\
\hline 10 & 12.00 & 67.00 & 20 & 19.00 & 19.00 \\
\hline
\end{tabular}


Table 2. The Fixed Demand, Maximum Demand and Minimum Demand of each Point

\begin{tabular}{c|l|l|l|l|l|l|l|l|l|l}
\hline Demand points & \multicolumn{1}{|c|}{1} & \multicolumn{1}{|c|}{2} & \multicolumn{1}{|c|}{3} & \multicolumn{1}{|c|}{4} & \multicolumn{1}{|c|}{6} & \multicolumn{1}{|c}{7} & \multicolumn{1}{|c}{8} & \multicolumn{1}{c}{9} & 10 \\
\hline Fixed demand & 30 & 20 & 25 & 28 & 22 & 25 & 21 & 29 & 23 & 27 \\
\hline Minimum demand & 15 & 10 & 12.5 & 14 & 11 & 12.5 & 10.5 & 14.5 & 11.5 & 13.5 \\
\hline Maximum demand & 45 & 30 & 37.5 & 42 & 33 & 37.5 & 31.5 & 43.5 & 34.5 & 40.5 \\
\hline Demand points & 11 & 12 & 13 & 14 & 15 & 16 & 17 & 18 & 19 & 20 \\
\hline Fixed demand & 20 & 30 & 25 & 22 & 28 & 25 & 29 & 21 & 26 & 24 \\
\hline Minimum demand & 10 & 15 & 12.5 & 11 & 14 & 12.5 & 14.5 & 10.5 & 13 & 12 \\
\hline Maximum demand & 30 & 45 & 37.5 & 33 & 42 & 37.5 & 43.5 & 31.5 & 39 & 36 \\
\hline
\end{tabular}

The plant growth simulation algorithm (PGSA) has been implemented in Matlab7.6 to solve the two models and the results are shown in Table 3.

Table 3. The Locations and the Profit under Different Number of Facilities

\begin{tabular}{|c|c|c|c|}
\hline $\begin{array}{l}\text { The number of new } \\
\text { facilities }\end{array}$ & Demand & Locations & Profit \\
\hline \multirow{2}{*}{$m=1(k=0)$} & Fixed demand & $(17,79)$ & 247.26 \\
\hline & Market expansion & $(11,67)$ & 289.73 \\
\hline \multirow{2}{*}{$m=2(k=0)$} & Fixed demand & $\begin{array}{ll}(17, & 79) \\
(35, & 22) \\
\end{array}$ & 478.07 \\
\hline & Market expansion & $\begin{array}{l}(11,67) \\
(38,58)\end{array}$ & 564.15 \\
\hline \multirow{2}{*}{$m=3(k=0)$} & Fixed demand & 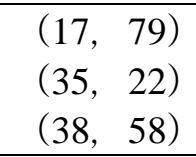 & 708.40 \\
\hline & Market expansion & $\begin{array}{ll}(11, & 67) \\
(38, & 58) \\
(35, & 22)\end{array}$ & 838.28 \\
\hline
\end{tabular}

As can be seen in Table 3, considering the market expansion, the location and the objective function have changed. When locating a new facility, the location is point $(17,79)$, while it is point $(11,67)$ with market expansion considered. When locating two facilities, the location is point $(17,79)$ and $(35,22)$, while it is point $(11,67)$ and $(38,58)$ with market expansion considered. When locating three facilities, the location is point $(17,79),(35,22)$ and $(38,58)$, while it is point $(11,67),(35,22)$ and $(38,58)$ with market expansion considered. The profits with market expansion considered increase by $17.18 \%, 17.67 \%$ and $18.33 \%$ respectively compared to fixed demand. Hence, market expansion has greatly affect the optimum solution and profits and it cannot be ignored when locating new facilities, especially for the facilities which are selling non-essentials.

When other parameters remain the same, just change $k$ from 0 to 1 , in other words, demand point $8(45,60)$ belongs to the retail company $A$. The plant growth simulation algorithm (PGSA) has also been implemented in Matlab7.6 and the results are shown in Table 4.

\section{Table 4. The Locations and the Profit under Different Number of Facilities}




\begin{tabular}{|c|c|c|c|}
\hline $\begin{array}{l}\text { The number of new } \\
\text { facilities }\end{array}$ & Demand & Locations & Profit \\
\hline \multirow{2}{*}{$m=1(k=1)$} & Fixed demand & $(50,7)$ & 284.66 \\
\hline & Market expansion & $(11,67)$ & 334.31 \\
\hline \multirow{2}{*}{$m=2(k=1)$} & Fixed demand & $\begin{array}{ll}(50, & 7) \\
(17, & 79) \\
\end{array}$ & 566.95 \\
\hline & Market expansion & $\begin{array}{ll}(11, & 67) \\
(35, & 22) \\
\end{array}$ & 660.71 \\
\hline \multirow{2}{*}{$m=3(k=1)$} & Fixed demand & 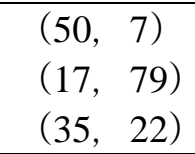 & 840.35 \\
\hline & Market expansion & $\begin{array}{ll}(11, & 67) \\
(35, & 22) \\
(38, & 58)\end{array}$ & 968.21 \\
\hline
\end{tabular}

The same conclusions can also be drawn from Table 4 as Table 3 . Besides that, comparing the results of Table 3 and Table 4, the optimum solution and profits are also changed greatly. The increase in profits can be easily understood-as there are more facilities belong to the retail company $A$, the larger probabilities of selecting the facilities of company $A$ and thus more profits. The optimum solution has also changed - although there are already facilities belongs to the retail company $A$, they are still "competitor" (to a certain extent) to the new facilities, the new facilities should not too close to them, so the optimum solutions are changed.

To compare the effects of market expansion on solving process, we draw the value of the objective function during the iterative process $(k=0)$, as shown in Figure 1 . The solid line represents the value of the objective function with market expansion, while the dotted line represents that with fixed demand. As can be seen in Figure 1, the curve is flat with fixed demand, while the curve is steep with market expansion. The profit with market expansion is more than that with fixed demand.

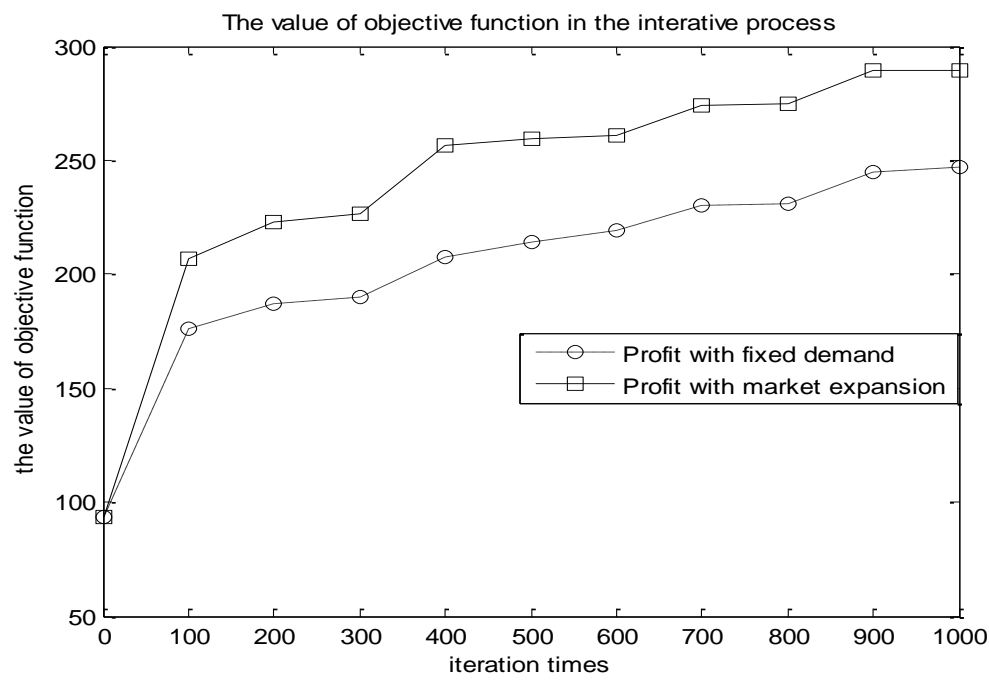

Figure 1. The Value of the Objective Function in the Iterative Process 


\section{Conclusions}

Location science has been an important topic of research. The selection of the right location is crucial to the company's success, especially when the facility has to compete for the customers' demand with other facilities. Company usually locate some new facilities in the same time, so in this paper, we extend the single-facility location to multi-facility location on the basis of literature [13]. A competitive multi-facility location model with fixed demand is put forward and then market expansion is taken into account. Taking market expansion into consideration makes the model more complex and harder to solve. In this paper, a plant growth simulation algorithm (PGSA) is developed and a small numerical example demonstrates its effectiveness. Compared to the problem with fixed demand, the optimum solution of facility location is variable and the profit increases obviously with market expansion considered. Hence, the company should define the property of goods and decide which kind of demand should be considered before locating new facilities. When the customer demand is elastic, it is better to locate the facilities with market expansion.

As for future research, consumer preference and different expressions of elastic demand should be considered in the model. New algorithm should also be put forward to solve the model and have a comparison with the Simulated Plant Growing Algorithm (PGSA).

\section{Acknowledgements}

This work has been funded by grants from the National Natural Science Foundation of China (71372013) and National Key Basic Research Program of China (2013JBM031).

\section{References}

[1] H. Hotelling, "Stability in Competition [J]", The Economics Journal, vol. 39, no. 153, (1929), pp. 41-57.

[2] F. Plastria and E. Carrizos, "Optimal Location and Design of a Competitive Facility [J]", Mathematical programming, vol. 100, no. 2, (2004), pp. 247-265.

[3] F. Yang, G. Huaa dn J. Li, "A New Model for Competitive Location and Algorithms [J]",Systems engineering theory and practice, vol. 7, (2006), pp. 18-24.

[4] X. Meng and X. Miao, "Study on Location Method of Single Location Center by Integrating Continuous and Discrete methods [J]", Journal of Harbin Institute of Technology, vol. 7, (2006), pp. 1055-1058.

[5] G. Duan, L. Chen, Y. Li, Z. Chen and R. He, "Bi- level Programming Model and Algorithm on Location of Logistics Distribution Center [J]", Journal of Transportation Systems Engineering and Information Technology, vol. 1, (2011), pp. 126-129.

[6] Dasci and G. Laporte, "Location and Pricing Decisions of a Multi-store Monopoly in a Spatial Market [J]", Journal of Regional Science, vol. 44, no. 3, (2004), pp. 489-515.

[7] Y. Yang and G. Zhou, "Study on Location Model of Facility Competition for Closed-loop Supply Chain Network with Random Demands [J]", Control and Decision, vol. 10, (2011), pp.1553-1561.

[8] Y. Bi and W. Li, "Research on Location Model with Discrete Collaborative Inventory and Fuzzy Demand [J]", Statistics and Decision, vol. 6, (2011), pp. 66-69.

[9] H A. Eiselt and G. Laporte, "Competitive Spatial Models [J]", European Journal of Operational Research, vol. 39, no. 3, (1989), pp. 231-242.

[10] Berman and D. Krass, "Locating Multiple Competitive Facilities: Spatial Interaction Models with Variable Expenditures [J]", Annals of Operations Research, vol. 111, nos. 1-4, (2002), pp. 197-225.

[11] R. Aboolian, O. Berma and D. Krass, "Competitive Facility Location Model with Concave Demand [J]", European Journal of Operational Research, vol. 181, no. 2, (2007), pp. 598-619.

[12] X. Zhang, C. Yang and $\mathrm{D}$. Hu, "The Competitive Location Problem with Market Expansion and Cannibalization [J]", Industrial Engineering and Management, vol. 2, (2009), pp. 43-47.

[13] J L. Redondo, J. Fernández and A G. Arrondo, "Fixed or Variable Demand? Does it Matter When Locating a Facility? [J]", Omega, the International Journal of Management Science, vol. 40, no. 1, (2012), pp. 9-20.

[14] D. Huff, "Defining and Estimating a Trading Area", Journal of Marketing, vol. 28, no. 3, (1964), pp. 34-38. 
[15] O. Berma and D. Krass, "Flow intercepting spatial interaction model: A new approach to optimal location of competitive facilities", Location Science, vol. 6, (1998), pp. 41-65.

[16] A. Ghosh, S. L. McLafferty and C. S. Craig, "Multi-facility retail networks, in: Z. Drezner (Ed.), Facility Location, Springer-Verlag, (1995), pp. 301-330.

[17] T. Li and Z. Wang, "Application of Plant Growth Simulation Algorithm on Solving Facility Location Problem [J]", Systems engineering theory and practice, 2008, (12):107-115.

\section{Authors}

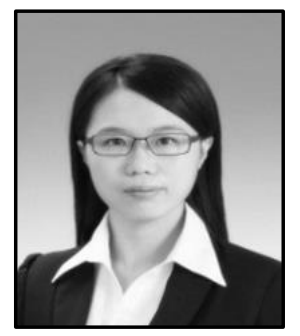

Guoying Wu, Female. Graduate. School of Economics and Management, Beijing Jiaotong University, Building of Siyuan East, Haidian District, Beijing 100044, China. Research Area: Competitive Location.

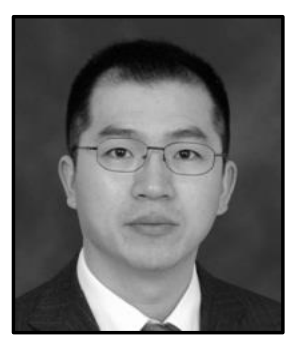

Jianqin Zhou, Male. Associate Professor. School of Economics and Management, Beijing Jiaotong University, Building of Siyuan, East Haidian District, Beijing 100044, China. Research Area: Location, Logistics network, Logistics management.

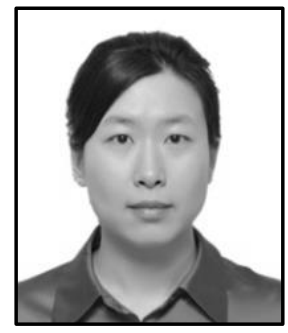

Bei Wang, Male, School of Public Administration, University of International Business and Economics, China. Research Area: Location. 